\title{
BRINGING SCIENCE TO THE FARMER
}

$\mathrm{T}$ HERE are many organizations, both within and outside the Government, the main task of which is to keep farmers up to date with new ideas, and to ensure that the relatively large sums spent on agricultural research are not wasted as a result of farmers not knowing about useful discoveries which have been made. A few years ago, the Agricultural Education Association set up a new section, the Advisory Methods Section, which has as its main interest methods of communicating with farmers. This Section has now held a number of meetings on this topic, and it has set up a committee which produced a report recommending that there should be more evaluation of advisory methods, and discussing ways in which this might be organized. The most recent venture in this field was for the Agricultural Education Association to hold a two-day conference based on the general theme of how to communicate with farmers. This conference was held on April 14-15 at Seale-Hayne Agricultural College, and an audience of 100 heard papers by a number of distinguished speakers from the academic and research world, as well as papers by those with considerable experience in conveying information to farmers.

The first day of the conference was devoted to the general theme of the farmer as a person, and the role of the farmer's family and of the farming community as a whole in encouraging him to adopt, or reject, new techniques. The conference was opened by Sir John Winnifrith, Permanent Secretary, Ministry of Agriculture, Fisheries and Food, who outlined the part played by the Government in agricultural research and in the communication of research results. The first paper was read by Prof. W. M. Williams, who dealt with the farmer and his family, and the importance of kinship networks in farming communities, for spreading now ideas, and even for lending and borrowing equipment. A paper by Dr. D. Sheppard dealt with attempts to find out objectively the extent to which farmers influence each other, and he concluded that although farmers may know about what other individual farmers are doing, in considerable detail, they have only rather hazy ideas about what the majority of the other farmers in their own districts are doing. As against this, there was evidence that information from 'other farmers' was a particularly convincing source of information, to a farmer who was considering adoptirg a new technique. It was suggested that the technique of conveying information to leader farmers was an economic way of disseminating information to a large number of others, with the advantage that this method was particularly likely to persuade other farmers to adopt the new techniques in question.

Mr. G. E. Jones discussed various aspects of leadership among farmers. He said it would be rare for one farmer to be the leader in many aspects of farming, and it would be likely that dairy farmers would have one leader and arable farmers another. He discussed the different functions which a leader might have, and distinguished between such types as the "innovator", the man who was the first to adopt the new farming technique, and the "legitimator", the farmer who was regarded by others as a sound man who would not adopt a technique unless it was wise to do so, so that when he had been observed to do so, others ceased to hesitate about whether they should adopt the technique.

Mr. H. T. Williams gave an address in which he discussed the farmer's understanding of the financial aspects of farming, and the ways in which farmers reached decisions on what to produce and how much. He felt that such decisions were usually made on a relatively naïve basis, using fairly simple calculations based on simple and perhaps misleading ideas on costs and profits.

Mr. A. W. Stobbs discussed the farmer's understanding of science. He pointed out that most farmers would have ceased their formal education at the age of fifteen or earlier, and that their training in science would probably have consisted of little more than 'rural science'. This was a real difficulty to the National Agricultural Advisory Service, which had the problem of telling farmers about new techniques, knowing that these would be more readily appreciated if the farmers concerned had a better understanding of science. Mr. Stobbs described one method for dealing with this which the National Agricultural Advisory Service had practised, in which 'academies' were held-these being one-day schools for farmers in which some particular farming topic was discussed completely and thoroughly, including some teaching on quite basic theories and hypotheses.

The second day of the conference dealt with sources of communication and their effect on farmers. In a paper dealing with the agricultural societies, Mr. C. V. Dadd discussed the part played by the societies in bringing new information to farmers, in particular by means of the agricultural shows. He outlined the results of recent surveys carried out at shows, which found what type of people came, and what they looked at when they did come. One finding was that farmers only looked at half the exhibits on a stand, on the average, and that they only learnt from a constant number of these, usually about five.

Mr. M. Messer dealt with the role of the farming Press, and claimed that farmers came next to doctors in the extent to which they were subjected to a barrage of information via the printed word. He commented on the problems of dealing with a wide range of interests among farmers, as well as a wide range of knowledge and reading ability. He emphasized the value of carrying out a survey among readers in such a situation, and described some results of an enquiry of this nature. Among other features of interest which this revealed was the fact that 60 per cent of the farmers have no books on farming. Thirty-seven read the agricultural Press, which nowadays contains a great deal of technical and scientific information.

Mr. B. P. Emmett dealt with sound radio as a method of communicating with farmers. He listed the various farming programmes run by the British Broadcasting Corporation, and gave figures showing what percentage of the farming population listened to each. He put forward his view that broadcasts on farming were unlikely to change a habit, and that the listener's power to select programmes was one cause of this. Audience research had shown the limitations of broadcasting as a teaching medium, and its lack of power to convince.

Television was the subject of a paper delivered by Mr. H. J. Hine, who, in particular, dealt with a programme for farmers put out regularly by the National Agricultural Advisory Service. He pointed out that there were occasions when having a visual demonstration could be a disadvantage for understanding, though it tended to increase attractiveness. He described the results of a survey which showed what topics had proved to be of most interest to farmers, and pointed out that, while it was not difficult to inform people by means of television, it was difficult to change people's attitudes or to convince them by this means.

Mr. A. R. Barfield considered the role of the associated industries and described the work done by the advisers 
in commercial firms. He pointed out that there were many more salesmen and commercial advisers than there were Government advisers, and that the former had to show results in order to keop their jobs. He described the methods of selling which are used, and emphasized that commercial firms have been using 'leader farmers' for some time now. The personal appioach is favoured rather than the mass approach. He pointed out that the less-efficient farmers are reached neither by commercial firms nor by the National Agricultural A.dvisory Service.

Mr. J. Gibbons spoke about the National Agricultural Advisory Service and in particular the problems attendant on advising farmers on an individual basis. On the average, each adviser has 700 farmers in his district, and on an individual basis he cannot do more than 350 visits a year. Advisers like this part of their work, and even though for some kinds of advice the visit might be an uneconomic method, even then it could establish a good relationship between the farmer and the adviser, which would help in any future contacts, even when mass media are to be used. For advice on some topics, where elaborate and detailed discussion were needed, no technique could replace the farm visit. He commented on the need for evaluation of advisory methods and referred to the report of the Agricultural Education Association Committee on Evaluation of Advisory Methods, which had called for more investigations of this nature.
Mr. A. J. Davies also dealt with the National Agricultural Advisory Service, but he was mainly concerned with advising by mass and group mothods. He stressed the necessity for reducing the number of individual visits and quoted the report of an investigation which showed that large changes could be produced with only a relatively small expenditure on mass media. The presentday trend was to favour small discussion groups rather than large meetings, or demonstrations.

There were lively discussions following each paper, and it was clear from these that there were many in the audience who had given much thought to problems concerning the best ways of communicating with farmers, and pioviding them with new information on scientific and technological problems. Nevertheless, although there are basic data about farmers and about what sources of information reach them, there are very few studies which were designed to examine the value of particular sources of information on farming for this purpose.

There is probably no other industry which is so well served with people whose main task it is to bring it up to date and to see that it makes full use of new scientific and technological findings. It is good to know that for those whose job it is to do this, the stage has arrived where expertise is not enough, and that those concerned are now applying research techniques to test the value of their own methods of communication.

D. SHEPPARD

\section{BARLEY GENETICS}

$\mathrm{T}$ HE first International Barley Genetics Symposium was held at Wageningen during August 26-30, 1963. The Symposium had been initiated by Dr. H. Lamberts of the Foundation for Agricultural Plant Breeding, Wageningen, and the programme had been discussed between several barley investigators following which an organizing committee had been established in the Netherlands to realize the plans.

The objective of the Symposium was to provide a survey of the present status of research in barley genetics. Several research workers had been invited to present the results of their recent investigations, in connexion with other results and problems in similar fields. In addition, other investigators were able to deliver short papers dealing with their investigations on more specialized topics. The lectures and the shorter contributions were grouped together according to subject. A general discussion was held after each session.

The Symposium began with an address of welcome by Dr. F. E. Nijdam, president of the organizing committee, and was opened officially by an address from Ir. J. G. Wellen, General Director of Agriculture in the Netherlands.

The first session, which dealt with the origin and phylogeny of barley, opened with an address by Bakhteyev (U.S.S.R.). First, the historical development of several discoveries and their related hypotheses and theories were reviewed. In addition, Bakhteyev discussed his own recent investigations with regard to the natural variability of the wild species Hordeum spontaneum. He had found in the southern parts of the U.S.S.R. some specimens of six-rowed wild barley, which he named $H$. langunculiforme. Later this species appeared to be conspecific with tworowed $H$. spontaneum, hence it should be considered as a sub-species of the latter. These findings, Bakhteyev considered, supported the theory of monophyletical descent of all cultivated barley forms from the wild species, H. spontaneum.

The two other contributors in this session arrived more or less at this theory of a monophyletical descent. Takahashi (Japan) came to this conclusion after investi- gating the geographical distribution of several genes, which might have been important in evolution. Zohary (Israel) criticized the suggestion that the origin of the six-rowed brittle barley types, like Aberg's H. agriocrithon and Bakhteyev's $H$. lagunculiforme, followed a possible hybridization between $H$. spontaneum and six-rowed cultivated barleys, which would result in a six-rowed brittle barley. Instead, he claimed that the first wild six-rowed barley has still to be found, and that the descent of barley for the time being must be considered to be monophyletic.

Mutation research was the subject of the second session, which opened with a review by Nilan et al. (United States) of chemical mutagenesis in barley. Investigations in this field have only been undertaken comparatively recently and the first period of screening has only just been completed. Nilan discussed the scoring of direct and indirect biological effects of chemical mutagens, their appearance and the methods of observing them. Furthermore, he gave a review of the various chemical mutagens, their methods of treatment, specific effects, etc. Special attention was directed to the influence of the environmental conditions, both during the treatment and during the observation of the effects.

Hagberg (also for Persson, Sweden), in his address, outlined the practical uses of mutation research in genetics, taxonomy and plant breeding. The use of translocations and the so-called erectoides mutants (short internode length) were discussed in detail. Both types of mutations are being used as genetic markers, while translocations have been further used to break linkage groups or to double special parts of the chromosomes; ert-mutations are being used in investigations of the finest structure of chromosomes or in plant breeding, so as to obtain varieties with short and stiff straw. However, this direct use of mutations in plant breeding is somewhat rare, and generally the mutagenic treatments are given to introduce a high and renewed variability in populations, so as to produce suitable material for selection.

In two contributions, results were presented of com. parative studies of the effects of ionizing radiation and 